\title{
BMJ Open How to increase the attractiveness of undergraduate rural clerkships? A cross-sectional study among medical students at two German medical schools
}

\author{
Sabine Herget, ${ }^{1}$ Melanie Nafziger, ${ }^{2}$ Stephanie Sauer, ${ }^{1}$ Markus Bleckwenn, ${ }^{1}$ \\ Thomas Frese, ${ }^{2}$ Tobias Deutsch (1) ${ }^{1}$
}

To cite: Herget S, Nafziger M, Sauer S, et al. How to increase the attractiveness of undergraduate rural clerkships? A

cross-sectional study among medical students at two German medical schools. BMJ Open 2021;11:e046357. doi:10.1136/ bmjopen-2020-046357

- Prepublication history and additional online supplemental material for this paper are available online. To view these files, please visit the journal online (http://dx.doi.org/10. 1136/bmjopen-2020-046357)

Received 29 0ctober 2020 Accepted 02 June 2021

Check for updates

(C) Author(s) (or their employer(s)) 2021. Re-use permitted under CC BY-NC. No commercial re-use. See rights and permissions. Published by BMJ.

${ }^{1}$ Department of General Practice, University of Leipzig, Faculty of Medicine, Leipzig, Saxony, Germany

${ }^{2}$ Institute of General Practice and Family Medicine, Martin-LutherUniversity Halle-Wittenberg,

Faculty of Medicine, Halle/Saale, Saxony-Anhalt, Germany

\section{Correspondence to}

Dr Tobias Deutsch;

tobias.deutsch@medizin.uni-

leipzig.de

\section{ABSTRACT}

Objectives While literature provides substantial evidence that undergraduate rural clerkships may contribute to attract medical students to rural careers, so far little is known about how to convince medical students to choose rural teaching sites for their clerkships, which is usually optional. Thus, this study aimed to investigate students' preferences and perceptions regarding different rural teaching and clerkship formats, important side conditions and suitable communication strategies to promote rural clerkships.

Design Cross-sectional study based on a quantitative survey among medical students in advanced study years. Setting Two German medical schools (Leipzig and HalleWittenberg).

Participants Medical students in third to fifth year (of six). Results Response rate was $87.1 \%$ with $n=909$ analysable questionnaires. Participants' mean age was 25.0 years and $65.2 \%$ were women. For $97.9 \%$ of the students completing some kind of rural clerkship was imaginable, for $90.8 \%$ even participation in a rural clerkship of 4 weeks and longer. Nearly half of the students $(48.0 \%)$ specified that a rural clerkship 4 weeks and longer was 'absolutely imaginable'. Younger age, having grown up in a rural or small-town region, being able to imagine future working in a small-town or rural area, and general practice as favoured, or at least conceivable career option were independently associated with a higher willingness to complete longer rural clerkships. Financial and organisational issues including remuneration of the clerkship, cost absorption for travelling and accommodation, and accessibility by public transport were the most important side conditions to increase the attractiveness of rural clerkships. Experience reports by fellow students, social media and informational events were stated to be the most suitable ways to advertise rural teaching offers.

Conclusions The majority of the students are openminded regarding even longer rural clerkships. This study adds new insights into measures that should be taken to convince them to actually chose this option.

\section{INTRODUCTION}

As with many other countries worldwide, Germany is currently faced with a dwindling
Strengths and limitations of this study

- Given the known positive impact of undergraduate rural experiences on rural career choice, this study provides new insights into measures that are useful to convince medical students to choose rural teaching sites for their clerkships, which is usually optional.

- The presented results are suitable to guide the implementation and development of undergraduate rural programmes as well as a prioritisation of important side conditions.

- The sufficient sample size, high response rate, participation of medical students from several years of study and inclusion of two medical schools situated in different federal states enhance the generalisability of the findings.

- As this cross-sectional study is partially based on declarations of intent, further research is needed to confirm that the concluded measures actually lead to an increased participation in rural clerkships.

supply of physicians in rural and smalltown areas. ${ }^{1-4}$ The reasons are complex and include, for example, demographic changes, a general trend towards urbanisation, infrastructural problems in rural areas, changed values among young physicians regarding the reconciliation of work and family life, as well as general recruitment problems in some specialties, particularly in general practice. ${ }^{35}$ There is an urgent need to take measures to attract a new generation of physicians to work in rural and small-town areas.

On the part of the medical schools, a lack of practical rural experiences and positive role models practising rural medicine during undergraduate medical education may have contributed to the low interest in rural workplaces among graduates. ${ }^{167}$ Subsequently, a number of medical schools worldwide have established different kinds of rural programmes offering, for example, rural 
clerkships, electives, on-site lectures and longitudinal curricula. ${ }^{18-10}$ It has been demonstrated in numerous studies that the exposure to rural curricula and particularly practical experiences in rural healthcare actually have the potential to positively influence medical students' future career decisions. ${ }^{189}$ To facilitate the implementation of new rural curricular offers, early involvement of students in the design process has been recommended. ${ }^{11}$

In Germany, undergraduate medical education takes 6 years and is divided into preclinical study section (basic science, years 1 and 2), clinical study section (clinical science, years 3-5) and a final year including three 4-month full-time clinical rotations (year 6). For detailed information regarding German undergraduate medical education, please refer to Chenot. ${ }^{12}$ During the last years, some German medical schools have implemented rural teaching projects or rural programmes as well. The nature and extent of these programmes is very different, ranging from rural summer schools and the organisational and financial support of specific rural general practice clerkships for subgroups of students to a general on-site teaching at rural branches of medical schools. ${ }^{13-17}$ As in many other countries, participation in undergraduate rural teaching offers is usually optional for the students.

Funded by the German Federal Ministry of Health, the Universities of Leipzig and Halle-Wittenberg are currently developing and establishing a new rural curriculum named 'MiLaMed'. The programme's aim is to provide rural teaching content longitudinally during the whole course of studies and to specifically promote clerkships in selected collaborating rural and small-town regions of the German federal states of Saxony and Saxony-Anhalt. In order to reach as many students as possible, the new teaching content is integrated into the regular compulsory and optional compulsory curriculum and all kinds of clerkships during undergraduate medical education will be promoted, regardless of specialty or setting (outpatient care or hospital). This is a particularity of the MiLaMed project, as most undergraduate rural programmes in Germany are focused only on general practice. However, the completion of rural clerkships remains optional in our programme. Students freely decide whether to complete a certain clerkship at a rural or an urban teaching site. Consequently, it is of particular importance to create conditions that are suitable to attract students to the rural offers.

As mentioned, there is substantial international evidence regarding the positive impact of undergraduate rural placements on rural career considerations and rural practice after graduation. However, although the choice of rural teaching sites for clerkships is voluntary for medical students in many countries, less is known about how to convince them to choose this option. Thus, the aim of this study was to find out which conditions are important for encouraging current medical students to choose rural clerkships, which kinds of rural clerkships and teaching formats are preferred, and which communication channels are suitable to promote these offers. Furthermore, it was of interest if there are different subgroups of students with different needs, for example, depending on regional background, career preferences or gender. The results were used to directly guide the development of the MiLaMed project and may also help to develop undergraduate rural initiatives in other regions and countries.

\section{METHODS}

\section{Sampling and design}

The present analysis is based on a cross-sectional quantitative survey among third to fifth year (of six) medical students, which was conducted in May and June 2019 at two German medical schools, Leipzig and HalleWittenberg. Students were asked to complete the paperbased anonymous questionnaire on a voluntary basis during academic courses. All students were comprehensively informed about the survey and its purpose.

\section{Questionnaire}

The questionnaire was self-developed on the basis of existing literature in a multilevel revision process involving social scientists, medical teachers and medical students. Prior to the survey, the questionnaire was pretested with five medical students representing the target group. To ensure face validity, comprehensibility and suitability, we followed the method of Concurrent Think Aloud in addition to general feedback by the participants. Students were asked to verbalise every action or thought while completing the questionnaire. The resulting think aloud protocols were analysed and led to minor modifications and amendments in the final version of the questionnaire. Besides relevant sociodemographic variables, the questionnaire contained items assessing career plans and previous experience with rural topics at medical school, students' readiness to take part in clerkships and teaching formats of various lengths at a rural teaching site, the potential of various side conditions to increase the attractiveness of rural clerkships, and the potential of various ways advertising could be used to convince medical students to take part in rural teaching offers. An English translation of the questionnaire items analysed in this paper is given in online supplemental file 1 .

\section{Statistical analysis}

Data were analysed using IBM SPSS Statistics V.25 for Windows. Frequencies were presented as $\%_{\text {valid }}\left(\mathrm{n}_{\text {absolute }} /\right.$ $\mathrm{n}_{\text {valid }}$ ), considering missing values for single items. Continuous variables were presented as mean \pm SD. Besides descriptive analysis, $\chi^{2}$ test was used to compare frequencies between groups. Differences in central tendency were compared with Mann-Whitney U test. Additionally, multivariable binary logistic regression was performed to reveal variables independently associated with the definite willingness to take part in a rural clerkship of 4 weeks or longer (dichotomous variable created based on the respective items). Considering the lack of a pre-existing theoretical model, we chose stepwise forward likelihood 


\begin{tabular}{|c|c|c|}
\hline Variable & $\mathrm{n}$ valid & n (\%)* \\
\hline Age (years, mean $\pm S D$ ) & 903 & $25.0 \pm 3.5$ \\
\hline Female & 906 & $591(65.2)$ \\
\hline In a relationship & 894 & $520(58.2)$ \\
\hline Has children & 870 & $66(7.6)$ \\
\hline Current year of study (of six) & 905 & \\
\hline ... third year & & $195(21.5)$ \\
\hline ... fourth year & & $226(25.0)$ \\
\hline ... fifth year & & $484(53.5)$ \\
\hline $\begin{array}{l}\text { At least one parent with higher } \\
\text { education degree }\end{array}$ & 899 & $701(78.0)$ \\
\hline Being a physician's child & 901 & $233(25.9)$ \\
\hline $\begin{array}{l}\text { Family or friends in general } \\
\text { practice }\end{array}$ & 901 & $244(27.1)$ \\
\hline Mainly grew up in: & 901 & \\
\hline ... big city & & $315(35.0)$ \\
\hline ... small town & & $288(32.0)$ \\
\hline ... rural area & & $298(33.1)$ \\
\hline $\begin{array}{l}\text { Pre-existing concluded education } \\
\text { in a medical vocational education }\end{array}$ & 898 & $213(23.7)$ \\
\hline Can imagine future working ... & 909 & \\
\hline$\ldots$ in a small-town & & $842(92.6)$ \\
\hline$\ldots$ in a rural area & & $402(44.2)$ \\
\hline Can imagine future living ... & 909 & \\
\hline ... in a small-town & & $611(67.2)$ \\
\hline$\ldots$ in a rural area & & $466(51.3)$ \\
\hline
\end{tabular}

*Unless otherwise indicated.

ratio (LR) model building. For model building, we considered all relevant variables with univariable group differences on a significance level of $p<0.20$ as a screening criterion (as far as there was no high correlation or content-related redundancy with another variable). In general, statistical significance was assumed for a probability of error of $\mathrm{p}<0.05$.

\section{Patients and public involvement}

Neither participants nor the public were involved in the design or conduct of this study.

\section{RESULTS}

\section{Questionnaire response and sample characteristics}

Out of 1044 medical students of both medical schools who were asked to take part in the study, 909 returned duly completed questionnaires, corresponding to a response rate of $87.1 \%$.

Potentially relevant sociodemographic characteristics of the participating students as well as attitudes regarding future working and living in a rural or small-town area are displayed in table 1. Regarding their current career preferences, $53.9 \%(489 / 907)$ stated that general practice was an imaginable option, while $9.3 \%$ (84/907) declared this as their favoured specialty. Working in ambulatory care was conceivable for $58.4 \%(530 / 908)$ and favoured choice of $37.6 \%(341 / 908)$. Working self-employed in their own practice was an option for $60.4 \%(548 / 908)$ and favoured by $30.4 \%$ (276/908). The majority of students $(75.2 \%$; 682/907) reported that they have been already confronted with topics of rural medical care during their medical studies.

\section{Willingness to take part in different rural teaching formats}

An overview regarding the willingness among medical students in our sample to take part in different types of teaching formats and clerkships of various lengths in rural regions is given in figure 1. Teaching formats are sorted in a descending order by frequencies of positive consideration. Altogether, $97.9 \%$ (880/899) of the participants stated that they could basically imagine taking part in at least one of the teaching formats presented for selection in our questionnaire ('rather imaginable' or 'absolutely imaginable' was stated for one or more of the respective items). For $90.8 \%(813 / 895)$ participation in a rural clerkship of 4 weeks and longer was conceivable ('rather imaginable' or 'absolutely imaginable' was stated for one or more of the four respective clerkship formats). Nearly half of the students $(48.0 \%$; 430/895) specified that a clerkship in a rural area of 4 weeks and longer was 'absolutely imaginable'.

We performed multivariable binary logistic regression to characterise the subgroup of those students with a high willingness regarding rural clerkships of 4 weeks and longer ('absolutely imaginable'). The results are presented in table 2. Our analysis revealed that younger age, having grown up in a small-town or a rural area (vs big city), being able to imagine working in a small-town or rural area (vs big city) in the future and general practice as an imaginable or favoured career option (vs no option) are significantly positively associated with reporting a clerkship of 4 weeks or longer at a rural site being 'absolutely imaginable'.

\section{Potential of different communication methods to advertise for rural clerkships}

The participating students' assessments of different communication types regarding its potential to advertise for rural clerkships are displayed in figure 2 (sorted in a descending order by means). The five most important methods comprise reports of rural experience by fellow students, advertisement via social media, informational events, organised group trips to a region ahead of the decision for a clerkship and advertisement through the respective medical school's official online student portal. Explorative subgroup comparisons regarding the potential of different means of communication depending on the variables sex, age and having grown up in a small-town or rural area revealed no differences of serious practical relevance. Women tended to assess slightly more positive 
In which courses/clerkships in a rural region can you imagine taking part to be the most likely?

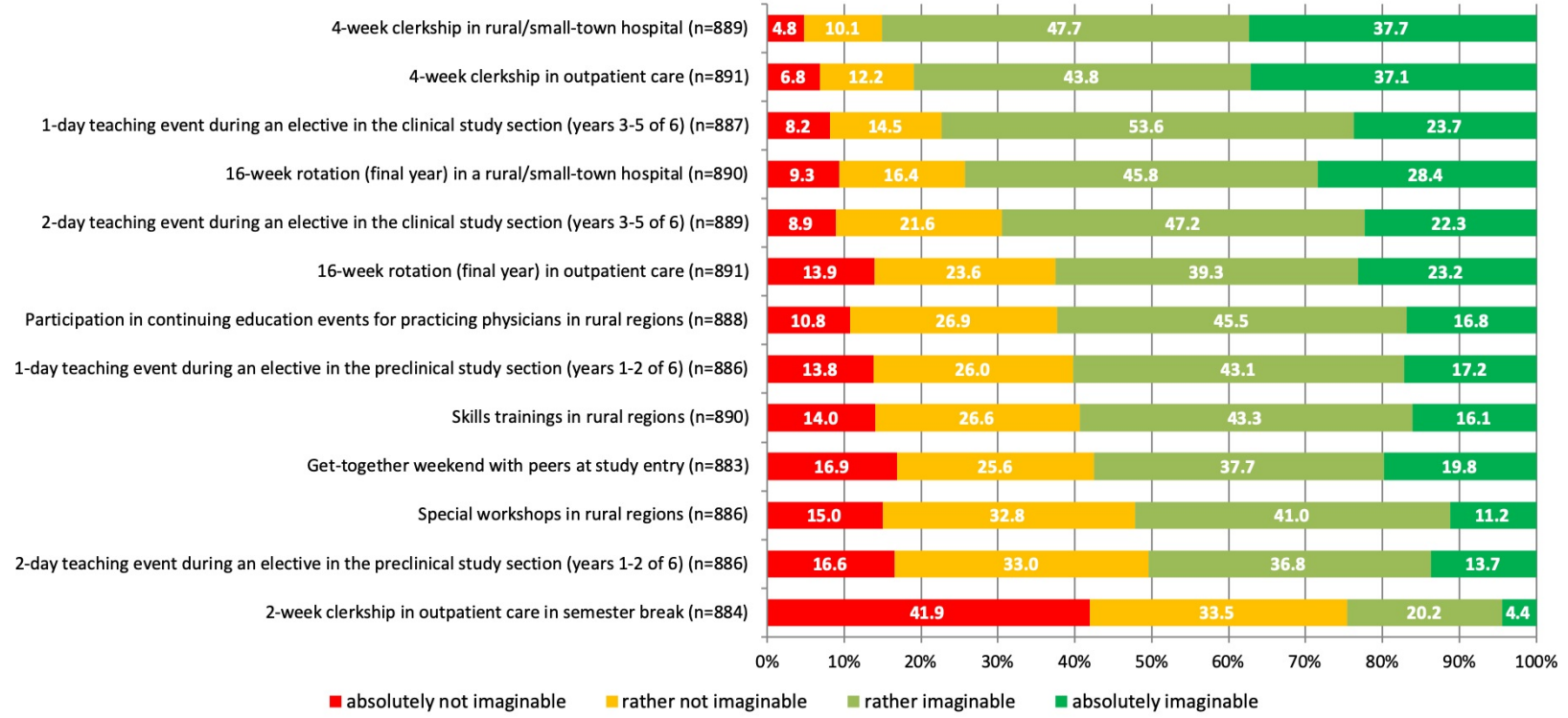

Figure 1 Medical students' willingness to take part in different types of teaching formats in rural regions (sorted in descending order by relative frequencies).

in general and students with rural or small-town background showed a slightly higher interest in informational events (data not shown).

Potential of various side conditions to increase the attractiveness of rural clerkships

An overview on the participating students' assessment of various side conditions regarding its potential to increase the attractiveness of rural clerkships is given in figure 3. The results are sorted in a descending order by relative frequencies of 'medium' to 'very strong' increase in attractiveness. The most important side conditions for medical students in our sample were remuneration for rural clerkships, reimbursement of travel expenses, accessibility by public transport, free accommodation and a physician mentor giving feedback on-site.

Participants were additionally asked which characteristics of a rural region itself might increase the attractiveness of a rural placement there (again a scale from 0

Table 2 Logistic regression analysis predicting definite willingness to take part in a rural clerkship of 4 weeks or longer $(\mathrm{N}=861)$ (at least one or more of the four respective clerkship formats was stated to be 'absolutely imaginable' vs 'rather'/'rather not'/'not at all imaginable')

Variables included in the model

(stepwise forward likelihood ratio LR)

Age (years)

Mainly grew up in:

... small town (vs big city)

... rural area (vs big city)

Future work in small-town or rural area is conceivable (vs not conceivable)

General practice is:

... an imaginable career option (vs no option)

... the favoured career option (vs no option)

Working in ambulatory care is:

... an imaginable career option (vs no option)

... the favoured career option (vs no option)

Further variables considered (due to univariable differences at $p<=0.2$ ), but not included in the model during the stepwise forward LR process: women (vs men), at least one parent with higher education degree (vs not), working self-employed (own practice) in the future is 'an imaginable career option' (vs 'no option')/ is 'the favoured career option' (vs 'no option') 
We are aiming to attract more medical students to clerkships in specific rural areas of Central Germany in the future. Which methods of communication would most likely appeal to you?

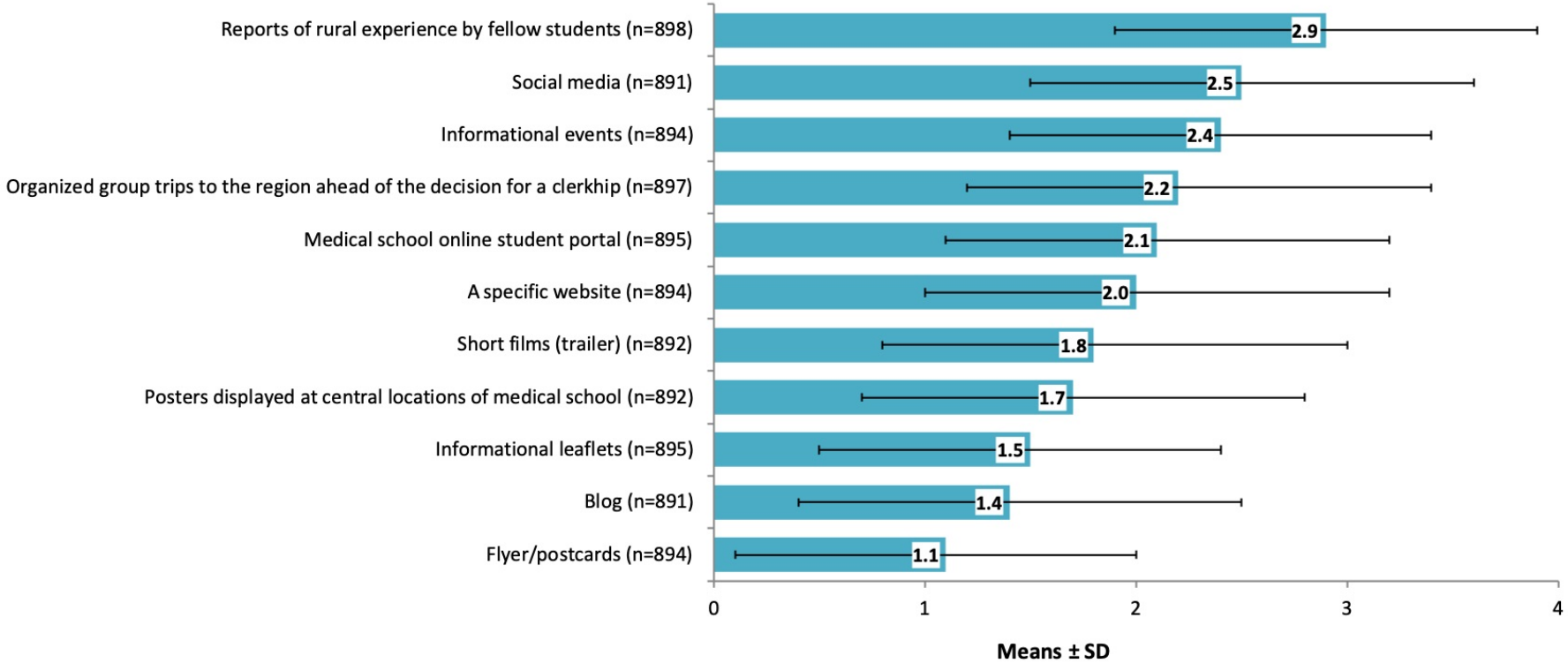

Scale: $0=$ no potential,$+1=$ low potential,$+2=$ medium potential,$+3=$ high potential,$+4=$ very high potential

Figure 2 Medical students' assessment of the potential of different communication methods to advertise for rural clerkships (sorted in descending order by means).

'no effect on attractiveness' to 4 'very strong increase in attractiveness' was used). A scenic landscape was stated to have the most impact $($ mean \pm SD: $3.0 \pm 1.0 ; \mathrm{n}=886)$, followed by interesting cultural events $(2.7 \pm 1.1 ; \mathrm{n}=890)$, interesting sports offers $(2.6 \pm 1.1 ; \mathrm{n}=891)$ and interesting offers regarding wellness and relaxation in the region $(2.2 \pm 1.2 ; \mathrm{n}=888)$.

Explorative subgroup comparisons regarding the potential of different side conditions depending on the variables sex, age and having grown up in a small-town or rural area showed a slightly positive correlation between higher age and the importance of on-site child care and a slightly negative correlation between higher age and the importance of common accommodation and leisure time with peers. Furthermore, women tended to assess all items slightly more positively (data not shown). In summary, we found no subgroup differences of serious practical relevance.

A content analysis of the additional open-ended question 'Which other aspects not mentioned in the

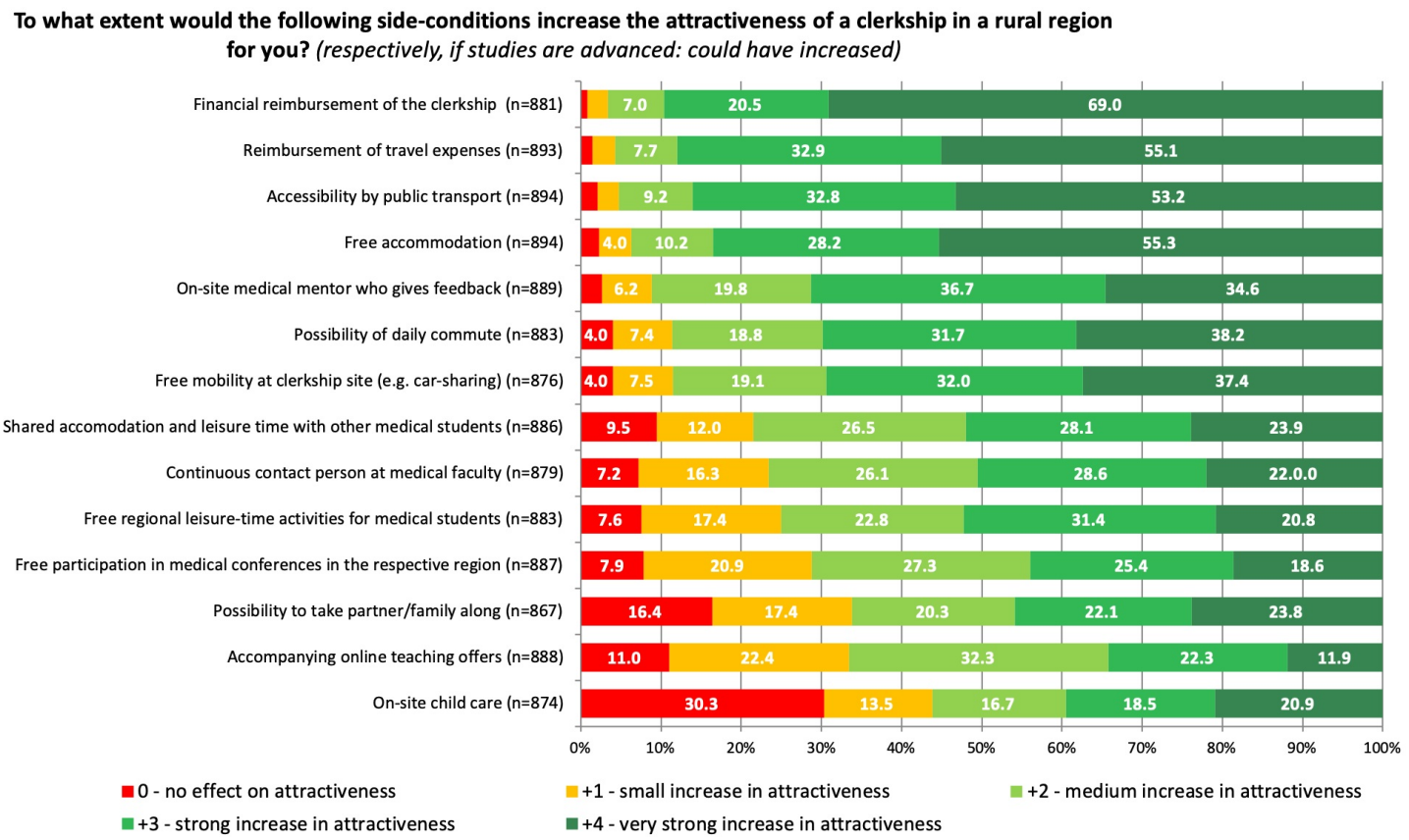

Figure 3 Medical students' assessment of the potential of various side conditions to increase the attractiveness of rural clerkships (sorted in descending order by relative frequencies). 
questionnaire would increase your willingness to participate in rural teaching events/clerkships?' revealed no further insights. Students' answers underlined once more the importance of financial support, free accommodation, access to (public) transport and a well-founded supervision by teaching physicians on-site.

\section{DISCUSSION}

\section{Summary of the main findings}

The overwhelming majority of the students in our sample were basically open-minded about completing some kind of rural clerkship and even participation in rural clerkships of 4 weeks and longer was imaginable for most participants. Four-week clerkships during the semester break were the most preferred rural teaching format. Younger age, having grown up in a rural or small-town region, being able to imagine working in a small-town or rural area in the future, and general practice as a favoured or at least a conceivable career option were independently associated with a higher willingness to complete longer rural clerkships. From the medical students' perspective particularly financial and organisational issues including remuneration of the clerkship, cost absorption for travelling and accommodation, and accessibility by the public transport were the most important side conditions to increase the attractiveness of rural clerkships. These were followed by the wish to have an on-site mentor giving feedback. Experience reports by fellow students, social media and informational events were stated to be the most suitable ways to advertise for rural clerkships. We found no indications for subgroups with relevantly different needs.

\section{Data interpretation and comparison with the literature}

In this study, nearly all students reported that they could imagine some kind of clerkship, social activity or advanced medical training in a rural region. Nevertheless, there were substantial differences regarding different teaching formats with a clear preference for 4-week clerkships and particularly low interest in a 2-week clerkship in outpatient care during semester break. While 9 out of 10 students stated that also a longer rural clerkship of 4 weeks and more is at least basically conceivable, this was even 'absolutely imaginable' for half of the participants. This is a very promising result, as it has been shown that particularly longer rural placements have positive effects on medical students' attitudes and career intentions regarding medical practice in rural areas, and may increase the number of graduates entering rural practice. ${ }^{11819}$

According to our findings, appropriate side conditions and advertisements have serious potential to additionally raise the attractiveness of rural clerkships for many students. In synopsis, our results imply that a substantial number of students might be convinced to participate in rural clerkships, if the right measures were taken. In a previous study among graduates from the medical school in Leipzig, about one third of all participants reported having gained any kind of rural experience during undergraduate education, and half of those, who had finally entered general practitioner careers. ${ }^{20}$ Considering the still ongoing lack of graduates entering rural practice, more students should gain respective experience, preferably in the course of longer clerkships.

We found that younger age, having grown up in a rural or small-town region, being able to imagine future rural practice and favouring or at least considering a career in general practice was associated with higher willingness to complete longer rural clerkships. Except for younger age these associated variables have been also described to be predictors of rural practice after graduation. ${ }^{1021-25}$ Thus, our findings imply that particularly those students with the highest probability for future rural practice have the greatest interest in longer rural clerkships during undergraduate education. This subgroup could be targeted most intensely to strengthen their interest and maintain it over the course of their studies. A targeted encouraging of students with rural backgrounds who are undecided as to where they would like to work in the future to participate in a rural programme has also been suggested by Barthen $e t a l .^{26}$ The association of younger age and higher willingness for longer rural undergraduate experiences in our study was new and might be promising as, in contrast to our findings, the outcome of 'ultimately working rurally after graduation' was associated with older age in previous studies. ${ }^{27} \mathrm{~A}$ possible explanation might be seen in a higher flexibility and independence of younger students. Wilhelmi et alfound in qualitative study including students as well as postgraduate young doctors that depending on life stage different factors were relevant regarding potential rural practice, like cultural offerings and the quality and accessibility of educational structures for the family. ${ }^{28}$

Regarding the importance of different side conditions that might increase the attractiveness of rural clerkships our results imply that students' ratings are largely homogeneous, as we couldn't find relevant differences depending on sex, age and regional background. Consequently, the side conditions rated as most important in our study would meet the needs of most students. Our findings particularly underline the importance of remuneration as well as cost absorption for accommodation and transport. The fact that students might be afraid of additional costs for travelling and accommodation with regard to rural clerkships has been emphasised previously. ${ }^{16}$ Considering the usually limited financial resources of students, the relevance of cost neutrality of rural clerkships seems absolutely comprehensible and should be addressed by targeted financial support. Another important factor increasing the attractiveness of rural clerkships was the accessibility of the teaching site by public transport, probably due to limited availability of a personal vehicle. As not all German rural teaching sites are accessible by public transport, unconventional measures such as the possibility of clerkship-related carsharing or car rental might help to overcome this barrier. 
This would also improve on-site mobility and enable daily commute by the students, which were highly rated side conditions in our study as well.

In our sample, besides financial and organisational aspects, the students' strong desire for a physician mentor giving feedback during the clerkship has been noted. In a previous study assessing students' needs regarding an optional rural teaching concept with a specific focus on general practice, about one-third of the participants expressed the wish for regular and detailed feedback from the teaching physician. ${ }^{26}$ Regarding possible effects on future rural career choice, supportive mentoring and positive rural physician role models have been shown to be a motivating factor. ${ }^{1629}{ }^{30}$ Rural physicians who are training medical students should be aware of the explicit relevance of this issue and should be trained in didactic and mentoring skills. Furthermore, it should be pointed out to the students that mentoring and the possibility to actively participate in patient care during clerkships are often particularly good at rural teaching sites due to small group learning environment, close relationships to medical teachers and more opportunities for hands-on experience. $^{31} 32$

With regard to characteristics of rural regions themselves our results indicate that especially the scenic landscape should be emphasised within communication strategies trying to convince students to apply for rural clerkships. While the results of Ross et al indicate a rather low interest of many students in exploring the rural region the clerkship is situated in, ${ }^{33}$ other authors have underlined that accompanying activities may help to increase the awareness of rural life style issues and cultural and recreational opportunities in the region. ${ }^{19}$

Our results provide new insights regarding the potential of different communication strategies to attract medical students to rural clerkships. Again, the respective ratings of the participants were largely homogeneous. Field reports by fellow students, who have already completed a rural clerkship, as well as social media, were of particular importance and should be definitely addressed by undergraduate rural programmes. The general impact of peer influence on study-related decisions has been previously underlined in other fields, for example, regarding the participation in study abroad. ${ }^{34}$ Social media marketing has been the focus of university communication only for a few years. However, its great potential in complementing a modern undergraduate medical education has been emphasised in a current review by Latif $e t a l .{ }^{35}$ Interestingly, the potential of on-site events (informational events, organised excursions to the rural area) to advertise for rural clerkships was highly rated by the students in our sample. Consequently, in order to promote students' interest in rural clerkships, advertisements could be explicitly placed in introductory lessons, lectures and specific informational events at the university. The potential of advertisement through the commonly established ways of communication at German medical schools, such as the online student portal, specific project websites as well as posters, was rated medium to low. Nevertheless, these ways of communication have potential to contribute to a comprehensive communication strategy. Print media like flyers and leaflets seem to be of minor importance for the students and could be neglected, and printing costs may be a factor particularly if small financial budgets are available.

\section{Strengths and limitations}

This study addresses an important issue of current healthcare relevance in many countries worldwide and provides additional knowledge regarding the measures that should be taken to attract medical students to rural experiences. Given a substantial body of evidence regarding the potential of undergraduate rural exposure to positively contribute to the recruitment of physicians practising in rural areas, the present findings add new insights into which teaching formats, side conditions and communication strategies should be taken into consideration when aiming at convincing more medical students to decide for rural clerkships. The sufficient sample size, high response rate, participation of medical students from several years of study, and inclusion of at least two medical schools situated in different federal states enhance the representativeness of the findings. As a limitation it can be discussed that this study was cross-sectional and partially based on declarations of intent. Assessing factors increasing the attractiveness of rural clerkships and the ability to imagine completing a rural clerkship cannot be put on the same level with actually taking part in it. Consequently, further studies should examine if the measures concluded to be important based on our data actually lead to an increased participation in rural clerkships. A second limitation might be that at least some of our findings could be more or less specific for the German undergraduate education system (eg, certain teaching formats). The self-developed questionnaire might also be seen as a limitation by some readers. On the other hand, it should be noted that we asked for relatively simple information instead of complex psychological constructs. Furthermore, the questionnaire was thoroughly developed based on literature by an experienced interprofessional team including members of the target group. With additional consideration of the detailed pretesting procedure, we assume validity with regard to content. Finally, it should be stated that we did not adjust for multiple testing when analysing potential subgroup differences for the single items regarding ways of communication and important side conditions due to the explorative nature of these additional analyses.

\section{Conclusion and implications for practice and research}

The vast majority of current German medical students seems to be open-minded towards the participation in rural teaching formats and even longer rural clerkships. Younger students, who have grown up in a rural or smalltown area, who consider general practice as a possible career option, and who are at least able to imagine future rural practice seem to have the highest interest in longer 
rural clerkships. This subgroup might be targeted specifically when promoting rural teaching offers. Our results concerning students' perceptions regarding the potential of various side conditions to increase the attractiveness of rural clerkships enable a prioritisation of important accompanying measures when aiming to attract undergraduates to rural teaching sites. An explicit remuneration of rural clerkships, cost absorption for travelling and accommodation, good accessibility of the clerkship site (preferably by public transport), free on-site mobility and a physician mentor giving feedback during the clerkship are the most important side conditions. When advertising clerkships in rural regions, particularly the charm of the scenic landscape should be emphasised, which could be considered for example when selecting pictures. Targeted communication strategies to promote rural clerkships should especially include positive experience reports by fellow students, advertisement through social media and informational events at university and in rural regions. The homogeneity of students' attitudes in our study implies that a broad spectrum of students could be convinced to complete rural clerkships by offering similar side conditions and using similar communication strategies. The results of our study may guide the (further) development and implementation of undergraduate programmes to attract medical students to rural clerkships including a targeted communication strategy. Our findings are of interest for teachers in undergraduate medical education, medical mentors and preceptors in rural regions, people involved in curriculum development and political stakeholders. Further research might examine possible differences between countries and if the application of the measures concluded from our study will actually lead to increased numbers of students completing rural clerkships. We are looking forward to report on the further development, evaluation and outcomes of our MiLaMed project in future publications.

Acknowledgements Sincere thanks to all students who supported our study by completing a questionnaire. Furthermore, we want to thank the district administrations of Nordsachsen, Vogtlandkreis, Anhalt-Bitterfeld and MansfeldSüdharz as well as all physicians and hospitals in these regions who are supporting our MiLaMed project.

Contributors SH contributed to questionnaire development, analysis and interpretation of the data, and drafting the manuscript. MN and SS contributed to questionnaire development and data acquisition and critically revised the manuscript. MB contributed to data interpretation and critically revised the manuscript. TF contributed to questionnaire development and data interpretation and critically revised the manuscript. TD contributed to conception and design of the study, questionnaire development, data acquisition, analysis and interpretation, and drafting the manuscript. All authors approved the final version of the article.

Funding This project is funded by the German Federal Ministry of Health (ZMVI12519FEP002) and additionally supported by the Ministry of Education and Cultural Affairs of Saxony, Germany.

Competing interests None declared.

Patient consent for publication Not required.

Ethics approval The local ethics committee (Ethical Committee at the Faculty of Medicine of the University of Leipzig) confirmed in writing that no formal ethical approval was necessary for this study. There was no personally identifiable information in this social research study among students. All participants were informed about the study's background, the survey was anonymous, and the statistically aggregated analysis of the data does not allow personal identification. Participation in the study was voluntary. Completing and returning the questionnaire was interpreted as consent to take part.

Provenance and peer review Not commissioned; externally peer reviewed.

Data availability statement The data may be obtained from the authors on reasonable request.

Supplemental material This content has been supplied by the author(s). It has not been vetted by BMJ Publishing Group Limited (BMJ) and may not have been peer-reviewed. Any opinions or recommendations discussed are solely those of the author(s) and are not endorsed by BMJ. BMJ disclaims all liability and responsibility arising from any reliance placed on the content. Where the content includes any translated material, BMJ does not warrant the accuracy and reliability of the translations (including but not limited to local regulations, clinical guidelines, terminology, drug names and drug dosages), and is not responsible for any error and/or omissions arising from translation and adaptation or otherwise.

Open access This is an open access article distributed in accordance with the Creative Commons Attribution Non Commercial (CC BY-NC 4.0) license, which permits others to distribute, remix, adapt, build upon this work non-commercially, and license their derivative works on different terms, provided the original work is properly cited, appropriate credit is given, any changes made indicated, and the use is non-commercial. See: http://creativecommons.org/licenses/by-nc/4.0/.

ORCID iD

Tobias Deutsch http://orcid.org/0000-0002-0936-6282

\section{REFERENCES}

1 Holst J. Increasing rural recruitment and retention through rural exposure during undergraduate training: an integrative review. Int J Environ Res Public Health 2020;17. doi:10.3390/ijerph17176423. [Epub ahead of print: 0309 2020].

2 Danish A, Blais R, Champagne F. Strategic analysis of interventions to reduce physician shortages in rural regions. Rural Remote Health 2019;19:5466.

3 Arentz C. Regionale Verteilung von Ärzten in Deutschland und anderen ausgewählten OECD-Ländern. Wissenschaftliches Institut der Privaten Krankenversicherungen (WIP) - Diskussionspapier, 2017. Available: http://www.wip-pkv.de/fileadmin/user_upload/Regionale_ Verteilung_von_AErzten_in_Deutschland.pdf [Accessed $22 \mathrm{Sep}$ 2020].

4 Advisory Council on the Assessment of Developments in the Health Care System. Needs-Based health care: opportunities for rural regions and selected health care sectors. Report 2014, abridged version, 2014. Available: https://www.svr-gesundheit.de/fileadmin/ user_upload/Gutachten/2014/SVR-Gutachten_2014_Kurzfassung_ engl.pdf [Accessed 16 Sep 2020].

5 Sachverständigenrat zur Begutachtung der Entwicklung im Gesundheitswesen. Bedarfsgerechte Versorgung -Perspektiven für ländliche Regionen und ausgewählte Leistungsbereiche. Gutachten, 2014. Available: https://www.svr-gesundheit.de/fileadmin/user_ upload/Gutachten/2014/SVR-Gutachten_2014_Langfassung.pdf [Accessed 16 Sep 2020].

6 Williamson MI, Wilson R, McKechnie R, et al. Does the positive influence of an undergraduate rural placement persist into postgraduate years? Rural Remote Health 2012;12:2011.

7 Curran V, Rourke J. The role of medical education in the recruitment and retention of rural physicians. Med Teach 2004;26:265-72.

8 Barrett FA, Lipsky MS, Lutfiyya MN. The impact of rural training experiences on medical students: a critical review. Acad Med 2011;86:259-63.

9 Strasser R, Couper I, Wynn-Jones J, et al. Education for rural practice in rural practice. Educ Prim Care 2016;27:10-14.

10 Johnson GE, Wright FC, Foster K. The impact of rural outreach programs on medical students' future rural intentions and working locations: a systematic review. BMC Med Educ 2018;18:196.

11 Bartlett M, Couper I, Poncelet A, et al. The do's, don'ts and don't knows of establishing a sustainable longitudinal integrated clerkship. Perspect Med Educ 2020;9:5-19.

12 Chenot J-F. Undergraduate medical education in Germany. Ger Med Sci 2009; 7:Doc02.

13 Herzog T, Brandhuber T, Barth N. "Beste Landpartie Allgemeinmedizin" (BeLA) - Didactical Concept against the Shortage of Family Physicians in Rural Areas. Zeitschrift für Allgemeinmedizin 2019;95:356-9. 
14 Schäfer H-M, Mangold B, Gerlach FM. The Fulda rural project encouraging young doctors to work in rural areas. Zeitschrift für Allgemeinmedizin 2015;91:260-3.

15 Seeger L, Becker N, Ravens-Taeuber G, et al. "Landpartie 2.0" - Conceptual development and implementation of a longitudinal priority program to promote family medicine in rural areas. GMS J Med Educ 2020;37:Doc29.

16 Kaduszkiewicz H, Teichert U, van den Bussche H. Ärztemangel in der hausärztlichen Versorgung auf dem Lande und im Öffentlichen Gesundheitsdienst. Eine kritische analyse der Evidenz bezüglich der Rolle von Aus- und Weiterbildung. Bundesgesundheitsblatt Gesundheitsforschung Gesundheitsschutz 2018;61:187-94.

17 Winkelmann A, Schendzielorz J, Maske D, et al. The brandenburg reformed medical curriculum: study locally, work locally. GMS J Med Educ 2019;36:Doc49.

18 Crump AM, Jeter K, Mullins S, et al. Rural medicine realities: the impact of immersion on urban-based medical students. J Rural Health 2019;35:42-8.

19 Henry JA, Edwards BJ, Crotty B. Why do medical graduates choose rural careers? Rural Remote Health 2009;9:1083.

20 Deutsch T, Lippmann S, Frese T. Gewinnung hausärztlichen Nachwuchses - Zusammenhang zwischen praxisorientierter Lehre und Karriereentscheidung. Gesundheitswesen 2014;76:26-31.

21 Kwan MMS, Kondalsamy-Chennakesavan S, Ranmuthugala G, et al. The rural pipeline to longer-term rural practice: general practitioners and specialists. PLoS One 2017;12:e0180394.

22 Mitra G, Gowans M, Wright B, et al. Predictors of rural family medicine practice in Canada. Can Fam Physician 2018;64:588-96.

23 Kondalsamy-Chennakesavan S, Eley DS, Ranmuthugala G, et al. Determinants of rural practice: positive interaction between rural background and rural undergraduate training. Med J Aust 2015;202:41-5.

24 Steinhäuser J, Joos S, Szecsenyi J, et al. Which factors increase the perception of settling a family practice in rural areas? Zeitschrift für Allgemeinmedizin 2013;89:10-15.

25 Asghari S, Kirkland MC, Blackmore J, et al. A systematic review of reviews: recruitment and retention of rural family physicians. Can $J$ Rural Med 2020;25:20-30
26 Barthen L, Ravens-Taeuber G, Paulitsch MA, et al. How can general practice be incorporated longitudinally in medical studies? students' views on the development of a new rural health program. GMS J Med Educ 2018;35:Doc42.

27 Puddey IB, Mercer A, Playford DE, et al. Medical student selection criteria and socio-demographic factors as predictors of ultimately working rurally after graduation. BMC Med Educ 2015;15:74.

28 Wilhelmi L, Ingendae F, Steinhaeuser J. What leads to the subjective perception of a 'rural area'? A qualitative study with undergraduate students and postgraduate trainees in Germany to tailor strategies against physician's shortage. Rural Remote Health 2018;18:4694.

29 Szafran O, Myhre D, Torti J, et al. Factors perceived to influence rural career choice of urban background family physicians: a qualitative analysis. Can Med Educ J 2020;11:e21-30.

30 Ray RA, Young L, Lindsay D. Shaping medical student's understanding of and approach to rural practice through the undergraduate years: a longitudinal study. BMC Med Educ 2018;18:147.

31 Caygill R, Peardon M, Waite C, et al. Comparing a longitudinal integrated clerkship with traditional hospital-based rotations in a rural setting. Med Teach 2017;39:520-6.

32 Denz-Penhey H, Murdoch JC. Is small beautiful? student performance and perceptions of their experience at larger and smaller sites in rural and remote longitudinal integrated clerkships in the rural clinical school of Western Australia. Rural Remote Health 2010;10:1470.

33 Ross BM, Cameron E, Greenwood D. A qualitative investigation of the experiences of students and preceptors taking part in remote and rural community experiential placements during early medical training. J Med Educ Curric Dev 2019;6:238212051985931.

34 Whatley M. Toward an understanding of peer influence on undergraduate study abroad participation. Frontiers 2018;30:51-71.

35 Latif MZ, Hussain I, Saeed R, et al. Use of smart phones and social media in medical education: trends, advantages, challenges and barriers. Acta Inform Med 2019;27:133-8. 